\title{
Genetic and environmental influences on obsessive-compulsive behaviour across development: a longitudinal twin study
}

\author{
G. Krebs ${ }^{1,2}$, M. A. Waszczuk ${ }^{1}$, H. M. S. Zavos ${ }^{1}$, D. Bolton ${ }^{3}$ and T. C. Eley ${ }^{1 *}$ \\ ${ }^{1}$ King's College London, MRC Social, Genetic and Developmental Psychiatry Centre, Institute of Psychiatry, Psychology and Neuroscience, De \\ Crespigny Park, London, UK \\ ${ }^{2}$ National and Specialist OCD and Related Disorders Clinic for Young People, South London and Maudsley NHS Foundation Trust, London, UK \\ ${ }^{3}$ King's College London, Department of Psychology, Institute of Psychiatry, Psychology and Neuroscience, De Crespigny Park, London, UK
}

Background. Little is known about the factors influencing the stability of obsessive-compulsive behaviour (OCB) from childhood to adolescence. The current study aimed to investigate: (1) the stability of paediatric OCB over a 12-year period; (2) the extent to which genetic and environmental factors influence stability; and (3) the extent to which these influences are stable or dynamic across development.

Method. The sample included 14743 twins from a population-based study. Parental ratings of severity of OCB were collected at ages $4,7,9$ and 16 years.

Results. OCB was found to be moderately stable over time. The genetic influence on OCB at each age was moderate, with significant effects also of non-shared environment. Genetic factors exerted a substantial influence on OCB persistence, explaining $59-80 \%$ of the stability over time. The results indicated genetic continuity, whereby genetic influences at each age continue to affect the expression of OCB at subsequent ages. However, we also found evidence for genetic attenuation in that genetic influences at one age decline in their influence over time, and genetic innovation whereby new genes 'come on line' at each age. Non-shared environment influenced stability of OCB to a lesser extent and effects were largely unique to each age and displayed negligible influences on OCB at later time points.

Conclusions. OCB appears to be moderately stable across development, and stability is largely driven by genetic factors. However, the genetic effects are not entirely constant, but rather the genetic influence on OCB appears to be a developmentally dynamic process.

Received 22 July 2014; Revised 24 October 2014; Accepted 25 October 2014; First published online 12 December 2014

Key words: Development, genetics, obsessive-compulsive disorder, paediatric research, twins.

\section{Introduction}

Obsessive-compulsive disorder (OCD) affects $1-4 \%$ of children and adolescents (Flament et al. 1988; Douglass et al. 1995; Heyman et al. 2001), and causes functional impairment in multiple domains (Piacentini et al. 2003). Although the disorder is often considered chronic and lifelong, there has been relatively little research into the stability of OCD in paediatric populations. The only meta-analysis to date of long-term outcomes in paediatric OCD included 521 participants from 16 studies (Stewart et al. 2004). A persistence rate of $41 \%$ for OCD and $60 \%$ for subclinical OCD

* Address for correspondence: T. C. Eley, Ph.D., MRC Social, Genetic and Developmental Psychiatry Centre, Institute of Psychiatry, Psychology and Neuroscience, King's College London, Box PO80, De Crespigny Park, London SE5 8AF, UK.

(Email: thalia.eley@kcl.ac.uk) symptoms was found over a mean follow-up period of 5.7 years. Similar persistence rates have been found in more recent studies (Micali et al. 2010; Mancebo et al. 2014). However, most studies to date have been limited by small sample sizes and short follow-up periods, and they typically focus on clinical cohorts rather than community samples (Stewart et al. 2004), and may therefore reflect the long-term effects of treatment rather than the natural course of the disorder.

A key question that has received little empirical attention is: what influences the persistence of OCD symptoms over time? Cross-sectional twin studies have found genetic factors to explain $45-65 \%$ of the variance of OCD symptoms at different ages during childhood and adolescence, with the remainder of the variance typically being explained by non-shared environmental influences (Eley et al. 2003; Hudziak et al. 2004; van Grootheest et al. 2005, 2008; Bolton et al. 2007; Hur \& Jeong, 2008; Taylor, 2011).

This is an Open Access article, distributed under the terms of the Creative Commons Attribution licence (http://creative commons.org/licenses/by/3.0/), which permits unrestricted re-use, distribution, and reproduction in any medium, provided the original work is properly cited. 
However, these studies do not inform us about the extent to which genetic and environmental factors drive stability of OCD symptoms over time.

To our knowledge, only two studies to date have investigated possible genetic and environmental contributions to OCD symptom stability, both using longitudinal twin designs (van Grootheest et al. 2007, 2009). The first explored stability of obsessive-compulsive behaviour (OCB) from ages 7 to 12 years (van Grootheest et al. 2007). OCB was found to be moderately stable over this interval and genetic factors explained approximately $40 \%$ of that stability, with the remaining variation accounted for by shared and non-shared environment. The second study examined the stability of OCB over an 11-year period among a cohort of young adults (van Grootheest et al. 2009). Again, they found a moderate level of phenotypic stability and genetic factors explained approximately $75 \%$ of OCB stability, with the remaining variance accounted for by non-shared environmental factors. Taken together, the results of these studies provide strong evidence that genetic factors influence the persistence of obsessive-compulsive symptomatology, but there might be developmental differences in the role of the environment. Moreover, it remains unclear whether these findings would extend to OCD symptom stability across a greater range of developmental stages, such as from early childhood through to adolescence. This is a period that is associated with significant biological and social changes, and a rising prevalence of OCD (Heyman et al. 2001).

Little empirical attention has been given to understanding the pattern of genetic risk for OCB across development. One possibility is that a single set of genes influences OCB at all ages. Alternatively, the effect of genes may vary over time, with different genetic factors influencing OCB at different stages of development. The two previous longitudinal twin studies of OCB provided clear evidence for genetic continuity but little evidence for genetic innovation (van Grootheest et al. 2007, 2009). This finding is in keeping with a number of other studies which suggest that genetic effects on child emotional development are largely stable and account for continuity in symptoms, whereas environmental influences tend to be timespecific and account for change in symptoms over time (O'Connor et al. 1998; Eaves \& Silberg, 2008; Trzaskowski et al. 2012; Zavos et al. 2012). However, some studies have found evidence of genetic continuity but also significant genetic innovation and attenuation (Scourfield et al. 2003; Lau \& Eley, 2006; Kendler et al. 2008a, b). For example, a study exploring genetic and environmental influences on mixed anxiety and depressive symptoms found that genetic factors influencing symptoms at age 8-9 years greatly declined in their effect by 19-20 years of age (i.e. attenuation), and new genetic influences emerged at later ages (i.e. innovation) (Kendler et al. 2008a). Different findings across studies may reflect methodological variations, including in the trait being measured and the time period over which is it assessed. It is possible that for some phenotypes genetic effects are stable over certain periods but not others. For example, genetic influences on depression may be dynamic during adolescence (Lau \& Eley, 2006) but stable in adulthood (Kendler et al. 1993). This highlights the importance of examining the temporal stability of genetic effects across different stages of development.

In summary, given the prevalence and morbidity associated with paediatric OCD, a better understanding of the long-term outcomes and factors influencing continuity and changes in obsessive-compulsive symptoms over time is needed. The current study addressed three related aims. First, given the limited research into the stability of OCD symptoms in large community samples of young people, we aimed to investigate the extent to which OCB is stable across development. More specifically, we explored the persistence of OCB severity over a 12 -year period from early childhood (age 4 years) to adolescence (age 16 years). Second, we tested the extent to which genetic and environmental factors determine the stability of OCB over time. Third, we investigated the extent to which genetic and environmental effects on OCD vary over time. We tested two possible models: that a single set of genetic/environmental risk factors make an impact on OCB across developmental stages; or that the influence of genetic/environmental factors on OCB varies over time through genetic innovation and attenuation.

\section{Method}

\section{Participants}

Participants were drawn from the Twins Early Development Study (TEDS), a large longitudinal study of twins born in England and Wales between 1994 and 1996 (Trouton et al. 2002). Details of recruitment and the sample are provided elsewhere (Haworth et al. 2013). TEDS was approved by the Institute of Psychiatry Ethics Committee and informed consent was obtained from participants. Zygosity of twins was determined using parental ratings of physical similarity (Price et al. 2000) and supplemented with DNA genotyping in a subsample for whom parent ratings were ambiguous. Participants were excluded if they did not provide consent, if they had severe medical disorders, experienced severe perinatal complications or if their zygosity was unknown $(6.6 \%$ of the overall sample).

All procedures contributing to this work comply with the ethical standards of the relevant national 
Table 1. Descriptive statistics and phenotypic correlations

\begin{tabular}{|c|c|c|c|c|}
\hline & Age 4 years & Age 7 years & Age 9 years $^{\mathrm{a}}$ & Age 16 years \\
\hline \multicolumn{5}{|l|}{ Sample size, $n$} \\
\hline MZ & 5072 & 5202 & 2421 & 3497 \\
\hline DZ & 9671 & 9216 & 4103 & 6150 \\
\hline Total & 14743 & 14418 & 6524 & 9647 \\
\hline \multicolumn{5}{|l|}{ Descriptive statistics } \\
\hline Mean age, years (s.D.) & $4.04(0.13)$ & $7.07(0.25)$ & $9.02(0.29)$ & $16.32(0.68)$ \\
\hline Cronbach's $\alpha$ for OCB scale & 0.59 & 0.59 & 0.62 & 0.61 \\
\hline Mean OCB score (s.D.) & $2.56(1.75)$ & $1.89(1.56)$ & $0.94(1.13)$ & $0.82(1.26)$ \\
\hline \multicolumn{5}{|l|}{ Phenotypic correlations } \\
\hline \multicolumn{5}{|l|}{ Age 4 years } \\
\hline$r$ & 1 & & & \\
\hline$n$ & 14743 & & & \\
\hline \multicolumn{5}{|l|}{ Age 7 years } \\
\hline$r(95 \% \mathrm{CI})$ & $0.45(0.43-0.46)$ & 1 & & \\
\hline$n$ & 11276 & 14418 & & \\
\hline \multicolumn{5}{|l|}{ Age 9 years } \\
\hline$r(95 \% \mathrm{CI})$ & $0.35(0.32-0.37)$ & $0.44(0.42-0.46)$ & 1 & \\
\hline$n$ & 5409 & 5771 & 6524 & \\
\hline \multicolumn{5}{|l|}{ Age 16 years } \\
\hline$r(95 \% \mathrm{CI})$ & $0.23(0.21-0.26)$ & $0.32(0.30-0.34)$ & $0.37(0.34-0.40)$ & 1 \\
\hline$n$ & 7891 & 8053 & 4054 & 9647 \\
\hline
\end{tabular}

MZ, Monozygotic; DZ, dizygotic; S.D., standard deviation; OCB, obsessive-compulsive behaviour; CI, confidence interval.

${ }^{a}$ At age 9 years, the study was restricted to just two out of three cohorts, resulting in a reduced sample size.

and institutional committees on human experimentation and with the Helsinki Declaration of 1975, as revised in 2008.

The current study included data from four waves of TEDS: age 4, 7, 9 and 16 years (see Table 1 for mean ages). The sample size at each time point, separated by zygosity, is shown in Table 1 . In total, 3224 individuals completed OCB items at all four time points. Individuals with data at all ages scored slightly lower on the OCB scale at age 4 years (mean $=2.48$ v. 2.59). Although this difference was significant $(t=3.22, p<0.001)$, the magnitude of the difference was small and not clinically meaningful. Drop-out rates were significantly higher for males than females $\left(\chi^{2}=54.66, p<0.001\right)$.

\section{Measures}

The measure of OCB severity was extracted from the parent-report Anxiety-Related Behaviour Questionnaire (ARBQ) (Eley et al. 2003). The ARBQ includes items to assess anxiety symptoms across diagnostic categories, including OCD. The questionnaire is not a diagnostic instrument but shares similarities with other widely used screening measures of child anxiety disorders (e.g. the Spence Children's Anxiety Scale; Spence et al. 2003) and OCD (e.g. the Short OCD Screener; Uher et al. 2007). All ARBQ items are rated on a three-point scale $(0=$ never, $1=$ sometimes, $2=$ often $)$.

Principal components analysis (PCA) was used to examine the factor structure of the ARBQ items at the ages of 7 and 16 years, in order to identify the items loading onto an OCB subscale. These analyses were not performed at the ages of 4 and 9 years given that the factor structure and OCB subscale had previously been established in the same sample (Eley et al. 2003; Hallett et al. 2009)t. In line with previous methods (Hallett et al. 2009), the PCA included an oblique rotation (Direct Oblimin command) and the number of factors was initially determined by using eigenvalues greater than 1 . The PCA revealed seven underlying factors at age 7 years, and four underlying factors at age 16 years (see online Supplementary Tables S1 and S2). However, at age 7 years the sixth and seventh factor did not represent a meaningful construct and therefore the PCA was repeated with five fixed factors (this did not affect items loading on OCB). At both the ages of 7 and 16 years, the third factor that emerged was comparable with the OCB factor identified previously (Eley et al. 2003; Hallett et al. 2009). In summary, the OCB subscale included: four

\footnotetext{
+ The notes appear after the main text.
} 
items at age 4 years (Eley et al. 2003); three items at age 7 years; two items at age 9 years (Hallett et al. 2009); and four items at age 16 years. The internal consistency and mean scores for the OCB subscale at each age are presented in Table 1.

\section{Analyses}

Phenotypic analyses

Composite scores for the OCB subscale at each age were calculated. In a small proportion of cases $(1.2 \%$ at age 4 years, $0.3 \%$ at age 7 years, $0.6 \%$ at age 9 years and $1.0 \%$ at age 16 years) there were missing OCB items. In these cases, the missing OCB item was calculated using the participant's mean OCB subscale score, with one missing item allowed per participant per time point. Within-subject phenotypic correlations over time were calculated to determine the stability of OCB. In order to obtain an initial gauge of heritability, cross-twin correlations were calculated at each age for monozygotic (MZ) and dizygotic (DZ) twins (e.g. twin 1 at age 4 years with twin 2 at age 4 years). Similarly, in order to obtain an initial gauge of genetic influences on OCB stability, cross-twin cross-age correlations were calculated (e.g. twin 1 at age 4 years with twin 2 at age 7 years).

\section{Model fitting}

The twin design compares the degree of phenotypic similarity between MZ twins, who share $100 \%$ of their genes, with DZ twins, who share $50 \%$ of their segregating genes on average. Within-pair correlations for MZ and DZ twins are compared in order to estimate the effects of: additive genetic factors (A); shared environment $(C)$, which is defined as aspects of the environment that contribute to phenotypic similarity between siblings; and non-shared environment (E), which is defined as environmental factors that give rise to phenotypic differences between siblings. Greater within-pair correlations among MZ twins versus DZ twins indicate genetic influences on the phenotype of interest. Within-pair similarity that is not accounted for by genetic factors is attributed to shared environmental effects. Non-shared environmental effects are estimated from the within-pair differences between $\mathrm{MZ}$ twins; this also includes measurement error. Where correlations between DZ twins are less than half that of MZ twins, dominant genetic effects (D) are tested using an ADE model (see Plomin et al. 2013).

Twin analyses were conducted using OpenMx within R (Boker et al. 2011), a structural equation modelling package for the analysis of genetically informative data that controls for non-independence of family member data. Variables were regressed for age and sex, as is standard practice for quantitative genetic model fitting (McGue \& Bouchard, 1984). Raw scores were normalized using Van der Warden transformations to correct for skew. Models were fitted using raw data maximum likelihood. The fit statistic provided by $\mathrm{Mx}$ for raw data modelling is minus twice the log likelihood (-2LL) of the observations. This is not an overall measure of fit but provides a relative measure of fit, because differences in -2LL between models are distributed as $\chi^{2}$. Therefore, the $-2 L L$ was compared with that of a saturated model in order to examine the overall fit of the genetic model. The fit of each sub-model was assessed by $\chi^{2}$ difference tests and the Akaike's information criterion (AIC $=\chi^{2}-2$ degrees of freedom), with lower $\chi^{2}$ values and more negative AIC values suggesting a better fit. When the difference between the AIC of two models was less than 10, the more parsimonious model was selected (Wagenmakers \& Farrell, 2004).

\section{Multivariate models}

We examined additive genetic (A), shared environment (C), dominant genetic (D) and non-shared environment (E) influences on OCB across development using a multivariate Cholesky decomposition. The Cholesky decomposition included the four OCB variables in temporal order (i.e. OCB at age 4, 7, 9 and 16 years). It assumes four distinct sets of genetic and environmental effects emerging at each time point (genetic and environmental innovation), which can exert influence on the variables at subsequent time points (see Fig. 1). $A_{1}, C_{1}$ and $E_{1}$ are common factor influences on the first variable (OCB at age 4 years) that can also influence the remaining three variables (OCB at ages 7, 9 and 16 years). $A_{2}, C_{2}$ and $E_{2}$ are new influences on the second variable and can also influence variables at the two later time points over and above the influences accounted for by $A_{1}, C_{1}$ and $E_{1}$. Similarly, $A_{3}, C_{3}$ and $E_{3}$ influence the third variable and can also influence the fourth variable over and above the influences accounted for by $A_{1}$, $C_{1}$ and $E_{1}$, and $A_{2}, C_{2}$ and $E_{2}$. Finally, $A_{4}, C_{4}$ and $E_{4}$ are unique influences emerging at the latest time point to influence the fourth variable only. Total A, C and $E$ effects on OCB at each age can be obtained by summing all paths to that measure.

The Cholesky decomposition can be represented as a multivariate correlated factors solution. It assumes that each variable has unique $\mathrm{A}, \mathrm{C}$ and $\mathrm{E}$ influences, and that these trait-specific influences are correlated with the A, C and E influences on other traits. The proportions of the phenotypic correlations accounted for by A, C and E influences were also calculated. 


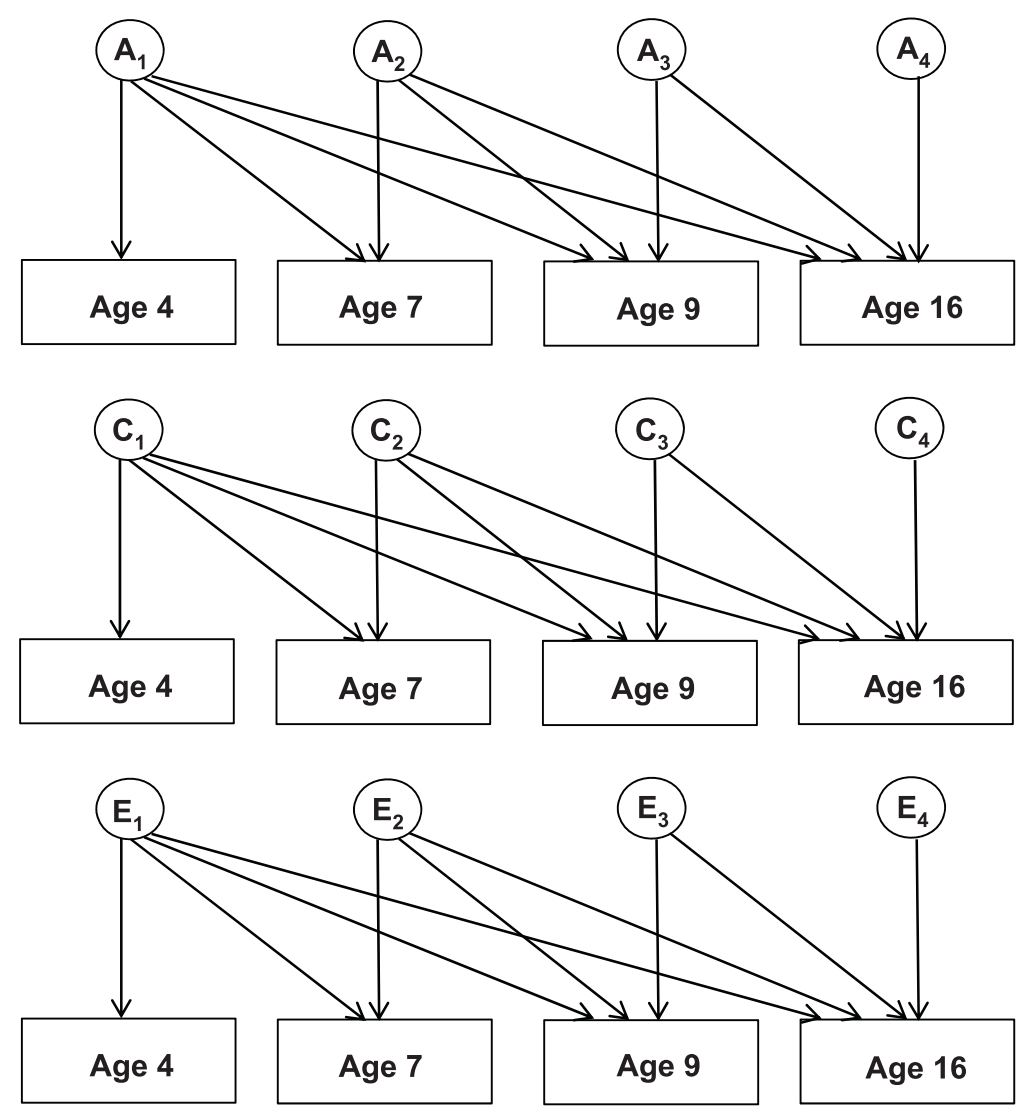

Fig. 1. Cholesky decomposition ACE model. A, Additive genetic parameters; C, shared environment parameters; E, non-shared environment parameters.

The relative fit of ACE and ADE models, with and without sex differences, was compared, and all models were compared with the saturated model. Quantitative and qualitative sex differences were tested to see whether males and females differ in magnitude or nature of genetic and environmental influences, respectively. Scalar sex differences were tested which assessed whether males and females showed differences in variance.

\section{Results}

\section{Phenotypic analyses}

The first aim was to establish the stability of OCD over time. Within-person phenotypic correlations over time were calculated. As shown in Table 1, overall the correlations indicated a moderate degree of stability in the expression of OCB. The strength of correlation reduced with increasing time intervals; the correlation was highest between the ages of 7 and 9 years $(r=0.45)$ and weakest between the ages of 4 and 16 years $(r=0.23)$.

\section{Multivariate analysis}

Multivariate analyses were conducted in order to address the second and third aims of the study, which were to establish the genetic and environmental influences on OCB stability and to test the extent to which these influences remained stable or changed over time. At each age, the within-age and across-ages twin correlations were higher among MZ than DZ pairs, indicating genetic influences on the OCB phenotype within time and longitudinally (see online Supplementary Table S3). In a number of instances, the $\mathrm{MZ}$ correlation was more than twice that of the DZ correlation, indicating possible dominant genetic effects. We therefore compared the relative fit of the ACE and ADE models; both models were tested with and without sex differences. Although the models including quantitative sex differences provided a better fit, the pattern of results was the same for both sexes and therefore a scalar model was selected. The scalar variable was included at all ages to account for different variances in OCB scores between males and females. The overall best-fitting model, according to the lowest 
Table 2. Proportion of phenotypic variance and covariance accounted for by $A, C$ and $E^{\mathrm{a}}$

\begin{tabular}{|c|c|c|c|c|}
\hline & Age 4 years & Age 7 years & Age 9 years & Age 16 years \\
\hline \multicolumn{5}{|c|}{ Proportion of phenotypic variance and covariance accounted for by A } \\
\hline Age 4 years & $0.59(0.57-0.61)$ & & & \\
\hline Age 7 years & $0.75(0.70-0.79)$ & $0.61(0.57-0.63)$ & & \\
\hline Age 9 years & $0.80(0.70-0.91)$ & $0.70(0.66-0.86)$ & $0.54(0.46-0.61)$ & \\
\hline Age 16 years & $0.78(0.68-0.97)$ & $0.59(0.43-0.75)$ & $0.72(0.57-1.00)$ & $0.33(0.26-0.41)$ \\
\hline \multicolumn{5}{|c|}{ Proportion of phenotypic variance and covariance accounted for by $\mathrm{C}$} \\
\hline Age 4 years & $0.00(0.00-0.01)$ & & & \\
\hline Age 7 years & $0.01(0.00-0.04)$ & $0.02(0.01-0.04)$ & & \\
\hline Age 9 years & $0.00(0.00-0.09)$ & $0.00(0.00-0.02)$ & $0.14(0.09-0.21)$ & \\
\hline Age 16 years & $0.10(0.00-0.25)$ & $0.17(0.04-0.30)$ & $0.00(0.00-0.12)$ & $0.25(0.19-0.31)$ \\
\hline \multicolumn{5}{|c|}{ Proportion of phenotypic variance and covariance accounted for by E } \\
\hline Age 4 years & $0.41(0.38-0.43)$ & & & \\
\hline Age 7 years & $0.24(0.20-0.28)$ & $0.38(0.36-0.40)$ & & \\
\hline Age 9 years & $0.21(0.15-0.27)$ & $0.30(0.26-0.35)$ & $0.32(0.29-0.35)$ & \\
\hline Age 16 years & $0.12(.03-0.20)$ & $0.24(0.18-0.30)$ & $0.28(0.21-0.36)$ & $0.42(0.39-0.45)$ \\
\hline
\end{tabular}

Data are given as proportion (95\% confidence interval).

A, Additive genetic parameters; C, shared environment parameters; E, non-shared environment parameters.

${ }^{a}$ The same pattern of results was found when we replicated the analyses using a stable index of obsessive-compulsive behaviour (i.e. the same three items at each age).

AIC value, was the ACE model. However, because some of the DZ correlations were less than half of the MZ correlations, A should be interpreted more broadly as both additive and dominant genetic effects. No parameters could be dropped from the model without deteriorating the fit. Multivariate model comparisons are presented in the online Supplementary Material (Table S4), along with the results of the ACE multivariate analyses with quantitative sex differences (online Supplementary Tables S5 and S6).

Parameter estimates for the proportion of variance and covariance in OCB accounted for by A, C and E within and across ages are presented in Table 2. As shown along the diagonal, moderate genetic influences on OCB were found at each age, ranging from 0.33 (at age 16 years) to 0.62 (at age 7 years). There was also a substantial influence of non-shared environment, ranging from 0.32 (at age 9 years) to 0.42 (at age 16 years). The effect of shared environment was not significant at age 4 years, and small at ages 4,9 and 16 years. The off-diagonal shows the effects of $A, C$ and $E$ on the covariance in OCB over time (i.e. OCB stability). Large genetic influences on $\mathrm{OCB}$ stability were found, ranging from 0.59 (age 7 to 16 years) to 0.80 (age 4 to 9 years). The effect of shared environment on OCB stability was generally not significant. However, significant small non-shared environmental influences on stability were found at all ages, ranging from 0.12 (age 4 to 16 years) to 0.30 (age 7 to 9 years).

The Cholesky decomposition informs us about the effect of stable and new genetic and environmental factors across the four ages. Parameter estimates are presented in Table 3. Results indicate genetic continuity, whereby genetic factors influencing $\mathrm{OCB}$ at any one age continue to affect OCB at subsequent ages. However, their influence declines over time, indicating genetic attenuation. For example, the first set of genetic factors $\left(A_{1}\right)$ accounted for $59 \%$ of the variance in OCB at age 4 years, but reduced to $19 \%$ by age 7 years, $13 \%$ by age 9 years and $6 \%$ by age 16 years. Furthermore, substantial new genetic factors emerged at each age, indicating genetic innovation. The new genetic effects that emerged at each age accounted for more than $50 \%$ of the total genetic influence on OCB at that time. The effect of non-shared environment was largely age specific. For example, the nonshared environmental factors influencing OCB at age 4 years $\left(E_{1}\right)$ had a negligible effect on OCB at age 7 years, and no significant effect at the ages of 9 and 16 years. Fig. 2 illustrates the genetic attenuation and innovation effects. Of note, the same pattern of results was found when we replicated the analyses using a stable index of OCB (i.e. the same three items at each age), demonstrating that the attenuation and innovation effects were not due to variation in the item content of the OCB measure at each age (see online Supplementary Table S7).

\section{Discussion}

This is the first study to examine the stability of severity of OCB from early childhood to late adolescence in 
Table 3. Cholesky decomposition results ${ }^{\mathrm{a}}$

\begin{tabular}{|c|c|c|c|c|}
\hline & A1 & A2 & A3 & $\mathrm{A} 4$ \\
\hline Age 4 years & $0.59(0.57-0.62)$ & & & \\
\hline Age 7 years & $0.19(0.16-0.22)$ & $0.42(0.38-0.45)$ & & \\
\hline Age 9 years & $0.13(0.09-0.17)$ & $0.08(0.04-0.13)$ & $0.33(0.26-0.40)$ & \\
\hline \multirow[t]{2}{*}{ Age 16 years } & $0.06(0.03-0.09)$ & $0.02(0.00-0.05)$ & $0.08(0.02-0.17)$ & $0.17(0.08-0.26)$ \\
\hline & $\mathrm{C} 1$ & $\mathrm{C} 2$ & $\mathrm{C} 3$ & $\mathrm{C} 4$ \\
\hline Age 4 years & $0.00(0.00-0.01)$ & & & \\
\hline Age 7 years & $0.01(0.00-0.04)$ & $0.01(0.00-0.04)$ & & \\
\hline Age 9 years & $0.00(0.00-0.19)$ & $0.14(0.00-0.20)$ & $0.00(0.00-0.20)$ & \\
\hline \multirow[t]{2}{*}{ Age 16 years } & $0.25(0.00-0.31)$ & $0.00(0.00-0.28)$ & $0.00(0.00-0.21)$ & $0.00(0.00-0.20)$ \\
\hline & E1 & E2 & E3 & $\mathrm{E} 4$ \\
\hline Age 4 years & $0.41(0.38-0.43)$ & & & \\
\hline Age 7 years & $0.03(0.02-0.04)$ & $0.35(0.33-0.37)$ & & \\
\hline Age 9 years & $0.01(0.00-0.02)$ & $0.04(0.03-0.05)$ & $0.27(0.25-0.29)$ & \\
\hline Age 16 years & $0.00(0.00-0.01)$ & $0.01(0.01-0.02)$ & $0.02(0.01-0.04)$ & $0.38(0.35-0.41)$ \\
\hline
\end{tabular}

Data are given as parameter estimate (95\% confidence interval).

A, Additive genetic parameters; C, shared environment parameters; E, non-shared environment parameters.

${ }^{a}$ Note that some of the zeros in the tables are due to rounding to two decimal places. The same pattern of results was found when we replicated the analyses using a stable index of obsessive-compulsive behaviour (i.e. the same three items at each age).

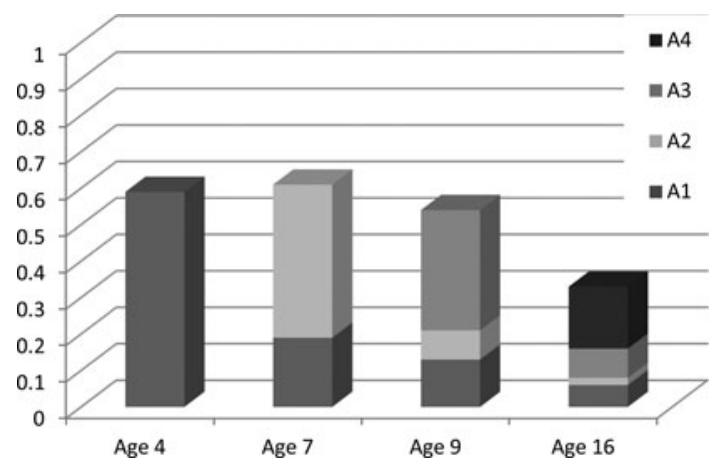

Fig. 2. The proportion of total variance in obsessivecompulsive behaviour (OCB) symptoms accounted for by stable and new genetic factors across development. The $y$-axis represents the total phenotypic variance. A1 represents the first genetic factor that is evident at age 4 years. A2 represents the second genetic factor that emerges at age 7 years. A3 is the third genetic factor that arises at age 9 years, and A4 is the fourth genetic factor that emerges at age 16 years. The total genetic influence on OCB at each age is the sum of all factors (A1, A2, A3 and A4) at that time point.

a large community sample. In relation to our first aim, we found that OCB severity was moderately stable across development. OCB was more likely to persist over shorter time intervals and relatively less stable over greater periods of time. These findings are in line with the results of the only previous study that has examined OCB longitudinally in an unselected community sample of children (van Grootheest et al.
2007). Our findings are also broadly consistent with outcomes found in adult community samples (van Grootheest et al. 2009).

The second aim was to examine the influences of genetic and environmental factors on the stability of childhood OCB. We found that persistence of OCB is largely driven by genetic factors, with up to $80 \%$ of stability being accounted for by genetic influences. Non-shared environmental factors also contributed to the stability of OCB over time but the effect was relatively small. These findings are broadly in keeping with previous research showing that genetic factors play a larger role in determining the stability of obsessive-compulsive symptoms over time than environment (van Grootheest et al. 2007, 2009). Genetic influences on OCB persistence have been estimated to be approximately $40 \%$ in child samples (van Grootheest et al. 2007) and 75\% in adult samples (van Grootheest et al. 2009). Our findings are consistent with the results of the adult study and suggest that the extent to which genes influence the continuity of OCB in childhood may be greater than previously thought.

The final aim was to explore the pattern of genetic and environmental influences on the severity of OCB across development. We found that the genetic factors influencing OCB at any one age continued to exert an effect on the expression of OCB at subsequent ages, suggesting that there is some continuity in the genes underlying OCB at different ages, which is in keeping with a number of previous studies in anxiety and 
depression (O'Connor et al. 1998; Trzaskowski et al. 2012; Zavos et al. 2012). However, we also found evidence for significant genetic attenuation, whereby the effect of a specific set of genes on OCB diminished over time, and genetic innovation, in which new genes appeared to 'come on line' at different ages. In other words, our findings suggest that the genetic architecture of OCB may vary across development. These findings are in line with previous research showing genetic attenuation and innovation in relation to internalizing disorders (Scourfield et al. 2003; Lau \& Eley, 2006; Kendler et al. 2008a, b). These data are also consistent with observations that OCD is a dynamic phenotype, and typically follows a waxing and waning course, with symptoms often changing over time (Rettew et al. 1992; Mataix-Cols et al. 2002). Interestingly, previous studies in OCB have found smaller genetic innovation than were obtained in the current study (van Grootheest et al. 2007, 2009). One possible explanation for this apparent discrepancy is that genetic innovation may be more evident at certain stages of development. For example, genetic influences on depression may be more stable in adulthood than adolescence (Kendler et al. 1993; Lau \& Eley, 2006). In the current study we investigated OCB over a particularly broad period of development and one that is associated with significant biological changes.

With respect to non-shared environment, we found that effects were largely age-specific, with little continuity of effects across development. An inherent limitation of twin modelling is that estimates of the non-shared environment are conflated by measurement error. It is possible that measurement error varied at each age due to the changing composition of the OCB measures, and it could be argued that this gave rise to the apparent attenuation and innovation effects. However, this is unlikely given that the same pattern of results was found when the analyses were repeated using a stable index of OCB (see online Supplementary Table S7). The finding that non-shared environmental influences are age-specific may reflect the fact that many unique environmental experiences are often time specific (e.g. bullying). While they may contribute to OCB in the short term, our findings suggest that they do not have a lasting effect on OCB. Similarly, previous studies have found non-shared environmental influences on anxiety to be time specific (Kendler et al. 2008b; Trzaskowski et al. 2012; Zavos et al. 2012).

The current study has a number of important clinical and theoretical implications. First, our findings demonstrate that severity of OCB is moderately stable across childhood. On the one hand, this can be viewed as providing a relatively optimistic message, in that OCB is not necessarily chronic. On the other hand, our findings show that compulsive behaviours emerging as early as 4 years of age can persist up to late adolescence. If these findings extend to clinically significant obsessive-compulsive symptoms, it would highlight the importance of early detection and intervention. Few studies have evaluated the treatment of OCD in young children (Comer et al. 2014; Freeman et al. 2014; Lewin et al. 2014), and further research is needed in this field. Second, our findings suggest that unique environmental experiences do not generally have an enduring effect on OCB traits, but rather their effects tend to be age specific. This finding supports the use of interventions that focus on 'the here and now' rather than past experiences, such as cognitive behaviour therapy, which is recommended as a first-line treatment for paediatric OCD (National Institute for Health and Clinical Excellence, 2005; Geller \& March, 2012). Third, our novel finding that genetic effects on the severity of OCB are developmentally dynamic has crucial implications for molecular genetic research. Our findings suggest that molecular genetic studies of OCD should be age sensitive, rather than assuming that the same genes influence OCD at different ages and pooling data from participants across a wide range of ages. In this vein, gene-age interactions have been found in the field of physical health, including in relation to blood pressure regulation (Simino et al. 2014), lipid levels (Dumitrescu et al. 2011) and obesity (Lasky-Su et al. 2008).

The current study has a number of strengths, including the large sample size and the long follow-up period. However, the results must also be considered in the context of a number of limitations. First, the measure of OCB used only included two to four items, and is therefore likely to have captured a narrow range of the OCD phenotype. Of particular note, the items included focused solely on compulsive behaviours and did not encompass obsessional thoughts. Furthermore, the OCB subscales had relatively low levels of internal consistency, indicating considerable heterogeneity between items. This may reflect the small number of items included, and future studies should seek to replicate the current findings using a more robust measure of OCB. Second, the OCB measure used is not a diagnostic instrument and it cannot be assumed that the current findings would necessarily apply to diagnosable OCD. However, previous research supports the notion that OCD is a dimensional, not categorical, construct thereby validating research in analogue samples (Abramowitz et al. 2014). Third, the current study only included parent-report OCB. It will be important for future research to include child-report measures, particularly given that the agreement between child- and parent-report of OCD symptoms has been shown to be relatively poor (Canavera et al. 2009). On the other hand, child-report 
scales of psychopathology are typically only validated for use from 7 years onwards (e.g. Saylor et al. 1984). Children are unlikely to be able to complete self-report scales before this age, which would have precluded the possibility of having a child-report measure at every time point in the current study. Lastly, the current study has a number of limitations that are inherent to twin design studies as previously described (Plomin et al. 2013).

Notwithstanding these limitations, this is the first study to examine the genetic and environmental influences on OCB severity over a 12-year period from childhood to adolescence. Our results suggest that the persistence of OCB over time is largely driven by genetic factors. However, genetic influences on OCB are not stable but rather the genetic architecture of OCB appears to change across development. This could potentially explain temporal fluctuations in symptoms that are common to the disorder.

\section{Supplementary material}

For supplementary material accompanying this paper visit http://dx.doi.org/10.1017/S0033291714002761

\section{Acknowledgements}

TEDS is supported by a programme grant (G0901245; and previously G0500079) from the UK Medical Research Council. G.K. receives salary support from the National Institute for Health Research (NIHR) Mental Health Biomedical Research Centre at South London and Maudsley NHS Foundation Trust and King's College London. M.A.W. was supported by a Ph.D. studentship funded by the Alexander von Humboldt Foundation. The views expressed are those of the authors and not necessarily those of the National Health Service, the NIHR or the Department of Health. We gratefully acknowledge the ongoing contribution of the participants in TEDS and their families.

\section{Declaration of Interest}

None.

\section{Note}

1 Although Hallett et al. (2009) conducted PCA on ARBQ items at age 7 years, their analyses were based on 25 out of 26 possible items. For the current study, the PCA was repeated including all 26 items.

\section{References}

Abramowitz JS, Fabricant LE, Taylor S, Deacon BJ, McKay D, Storch EA (2014). The relevance of analogue studies for understanding obsessions and compulsions. Clinical Psychology Review 34, 206-217.

Boker S, Neale M, Maes H, Wilde M, Spiegel M, Brick T, Spies J, Estabrook R, Kenny S, Bates T, Mehta P, Fox J (2011). OpenMx: an open source extended structural equation modeling framework. Psychometrika 76, 306-317.

Bolton D, Rijsdijk F, O'Connor TG, Perrin S, Eley TC (2007). Obsessive-compulsive disorder, tics and anxiety in 6-year-old twins. Psychological Medicine 37, 39-48.

Canavera KE, Wilkins KC, Pincus DB, Ehrenreich-May JT (2009). Parent-child agreement in the assessment of obsessive-compulsive disorder. Journal of Clinical Child and Adolescent Psychology 38, 909-915.

Comer JS, Furr JM, Cooper-Vince CE, Kerns CE, Chan PT, Edson AL, Khanna M, Franklin ME, Garcia AM, Freeman JB (2014). Internet-delivered, family-based treatment for early-onset OCD: a preliminary case series. Journal of Clinical Child and Adolescent Psychology 43, 74-87.

Douglass HM, Moffitt TE, Dar R, McGee R, Silva P (1995). Obsessive-compulsive disorder in a birth cohort of 18-year-olds: prevalence and predictors. Journal of the American Academy of Child and Adolescent Psychiatry 34, 1424-1431.

Dumitrescu L, Brown-Gentry K, Goodloe R, Glenn K, Yang W, Kornegay N, Pui CH, Relling MV, Crawford DC (2011). Evidence for age as a modifier of genetic associations for lipid levels. Annals of Human Genetics 75, 589-597.

Eaves LJ, Silberg JL (2008). Developmental-genetic effects on level and change in childhood fears of twins during adolescence. Journal of Child Psychology and Psychiatry 49, 1201-1210.

Eley TC, Bolton D, O'Connor TG, Perrin S, Smith P, Plomin R (2003). A twin study of anxiety-related behaviours in pre-school children. Journal of Child Psychology and Psychiatry 44, 945-960.

Flament MF, Whitaker A, Rapoport JL, Davies M, Berg CZ, Kalikow K, Sceery W, Shaffer D (1988). Obsessive compulsive disorder in adolescence: an epidemiological study. Journal of the American Academy of Child and Adolescent Psychiatry 27, 764-771.

Freeman J, Sapyta J, Garcia A, Compton S, Khanna M, Flessner C, FitzGerald D, Mauro C, Dingfelder R, Benito K, Harrison J, Curry J, Foa E, March J, Moore P, Franklin M (2014). Family-based treatment of early childhood obsessive-compulsive disorder: the Pediatric Obsessive-Compulsive Disorder Treatment Study for Young Children (POTS Jr) - a randomized clinical trial. JAMA Psychiatry 71, 689-698.

Geller DA, March J (2012). Practice parameter for the assessment and treatment of children and adolescents with obsessive-compulsive disorder. Journal of the American Academy of Child and Adolescent Psychiatry 51, 98-113.

Hallett V, Ronald A, Rijsdijk F, Eley TC (2009). Phenotypic and genetic differentiation of anxiety-related behaviors in middle childhood. Depression and Anxiety 26, 316-324.

Haworth CM, Davis OS, Plomin R (2013). Twins Early Development Study (TEDS): a genetically sensitive 
investigation of cognitive and behavioral development from childhood to young adulthood. Twin Research and Human Genetics 16, 117-125.

Heyman I, Fombonne E, Simmons H, Ford T, Meltzer H, Goodman R (2001). Prevalence of obsessive-compulsive disorder in the British nationwide survey of child mental health. British Journal of Psychiatry 179, 324-329.

Hudziak JJ, Van Beijsterveldt C, Althoff RR, Stanger C, Rettew DC, Nelson EC, Todd RD, Bartels M, Boomsma DI (2004). Genetic and environmental contributions to the Child Behavior Checklist obsessive-compulsive scale: a cross-cultural twin study. Archives of General Psychiatry 61, 608-616.

Hur YM, Jeong HU (2008). Sex differences in genetic and environmental influences on obsessivecompulsive symptoms in South Korean adolescent and young adult twins. Twin Research and Human Genetics 11, 314-320.

Kendler K, Gardner C, Lichtenstein P (2008a). A developmental twin study of symptoms of anxiety and depression: evidence for genetic innovation and attenuation. Psychological Medicine 38, 1567-1575.

Kendler KS, Gardner CO, Annas P, Neale MC, Eaves LJ, Lichtenstein P (2008b). A longitudinal twin study of fears from middle childhood to early adulthood: evidence for a developmentally dynamic genome. Archives of General Psychiatry 65, 421-429.

Kendler KS, Neale MC, Kessler RC, Heath AC, Eaves LJ (1993). A longitudinal twin study of 1-year prevalence of major depression in women. Archives of General Psychiatry 50, 843-852.

Lasky-Su J, Lyon HN, Emilsson V, Heid IM, Molony C, Raby BA, Lazarus R, Klanderman B, Soto-Quiros ME, Avila L, Silverman EK, Thorleifsson G, Thorsteinsdottir U, Kronenberg F, Vollmert C, Illig T, Fox CS, Levy D, Laird N, Ding X, McQueen MB, Butler J, Ardlie K, Papoutsakis C, Dedoussis G, O'Donnell CJ, Wichmann HE, Celedón JC, Schadt E, Hirschhorn J, Weiss ST, Stefansson K, Lange C (2008). On the replication of genetic associations: timing can be everything! American Journal of Human Genetics 82, 849-858.

Lau JY, Eley TC (2006). Changes in genetic and environmental influences on depressive symptoms across adolescence and young adulthood. British Journal of Psychiatry 189, 422-427.

Lewin AB, Park JM, Jones AM, Crawford EA, De Nadai AS, Menzel J, Arnold EB, Murphy TK, Storch EA (2014). Family-based exposure and response prevention therapy for preschool-aged children with obsessive-compulsive disorder: a pilot randomized controlled trial. Behaviour Research and Therapy 56, 30-38.

Mancebo MC, Boisseau CL, Garnaat S, Eisen JL, Greenberg B, Sibrava NJ, Stout RL, Rasmussen SA (2014). Long-term course of pediatric obsessive-compulsive disorder: three years of prospective follow-up. Comprehensive Psychiatry 55, 1498-1504.

Mataix-Cols D, Rauch SL, Baer L, Eisen JL, Shera DM, Goodman WK, Rasmussen SA, Jenike MA (2002). Symptom stability in adult obsessive-compulsive disorder: data from a naturalistic two-year follow-up study. American Journal of Psychiatry 159, 263-268.

McGue M, Bouchard TJ (1984). Adjustment of twin data for the effects of age and sex. Behavior Genetics 14, 325-343.

Micali N, Heyman I, Perez M, Hilton K, Nakatani E, Turner C, Mataix-Cols D (2010). Long-term outcomes of obsessive-compulsive disorder: follow-up of 142 children and adolescents. British Journal of Psychiatry 197, 128-134.

National Institute for Health and Clinical Excellence (2005). Obsessive-compulsive Disorder: Core Interventions in the Treatment of Obsessive-compulsive Disorder and Body Dysmorphic Disorder. NICE: London.

O'Connor TG, Neiderhiser JM, Reiss D, Hetherington EM, Plomin R (1998). Genetic contributions to continuity, change, and co-occurrence of antisocial and depressive symptoms in adolescence. Journal of Child Psychology and Psychiatry 39, 323-336.

Piacentini J, Bergman RL, Keller M, McCracken J (2003). Functional impairment in children and adolescents with obsessive-compulsive disorder. Journal of Child and Adolescent Psychopharmacology 13, 61-69.

Plomin R, DeFries J, Knopik V, Neiderhiser J (2013). Behavioral Genetics. Worth Publishers: New York.

Price TS, Freeman B, Craig I, Petrill SA, Ebersole L, Plomin R (2000). Infant zygosity can be assigned by parental report questionnaire data. Twin Research and Human Genetics 3, 129-133.

Rettew DC, Swedo SE, Leonard HL, Lenane MC, Rapoport JL (1992). Obsessions and compulsions across time in 79 children and adolescents with obsessive-compulsive disorder. Journal of the American Academy of Child and Adolescent Psychiatry 31, 1050-1056.

Saylor CF, Finch AJ, Spirito A, Bennett B (1984). The Children's Depression Inventory: a systematic evaluation of psychometric properties. Journal of Consulting and Clinical Psychology 52, 955-967.

Scourfield J, Rice F, Thapar A, Harold GT, Martin N, McGuffin P (2003). Depressive symptoms in children and adolescents: changing aetiological influences with development. Journal of Child Psychology and Psychiatry 44, 968-976.

Simino J, Shi G, Bis JC, Chasman DI, Ehret GB, Gu X, Guo $X$, Hwang S-J, Sijbrands E, Smith AV, Verwoert GC, Bragg-Gresham JL, Cadby G, Chen P, Cheng C-Y, Corre T, de Boer RA, Goel A, Johnson T, Khor C-C, Lluís-Ganella C, Luan JA, Lyytikäinen L-P, Nolte IM, Sim X, Sõber S, van der Most PJ, Verweij N, Zhao JH, Amin N, Boerwinkle E, Bouchard C, Dehghan A, Eiriksdottir G, Elosua R, Franco $\mathrm{OH}$, Gieger C, Harris TB, Hercberg $\mathrm{S}$, Hofman A, James AL, Johnson AD, Kähönen $M$, Khaw K-T, Kutalik Z, Larson MG, Launer LJ, Li G, Liu J, Liu K, Morrison AC, Navis G, Ong RT-H, Papanicolau GJ, Penninx BW, Psaty BM, Raffel LJ, Raitakari OT, Rice K, Rivadeneira F, Rose LM, Sanna S, Scott RA, Siscovick DS, Stolk RP, Uitterlinden AG, Vaidya D, van der Klauw MM, Vasan RS, Vithana EN, Völker U, Völzke H, Watkins H, Young TL, Aung T, Bochud M, Farrall M, Hartman CA, Laan M, Lakatta EG, Lehtimäki T, Loos RJF, Lucas G, Meneton P, Palmer LJ, Rettig R, Snieder H, Tai 
ES, Teo Y-Y, van der Harst P, Wareham NJ, Wijmenga C, Wong TY, Fornage M, Gudnason V, Levy D, Palmas W, Ridker PM, Rotter JI, van Duijn CM, Witteman JCM, Chakravarti A, Rao DC (2014). Gene-age interactions in blood pressure regulation: a large-scale investigation with the CHARGE, Global BPgen, and ICBP Consortia. American Journal of Human Genetics 95, 24-38.

Spence SH, Barrett PM, Turner CM (2003). Psychometric properties of the Spence Children's Anxiety Scale with young adolescents. Journal of Anxiety Disorders 17, 605-625.

Stewart S, Geller D, Jenike M, Pauls D, Shaw D, Mullin B, Faraone S (2004). Long-term outcome of pediatric obsessive-compulsive disorder: a meta-analysis and qualitative review of the literature. Acta Psychiatrica Scandinavica 110, 4-13.

Taylor S (2011). Etiology of obsessions and compulsions: a meta-analysis and narrative review of twin studies. Clinical Psychology Review 31, 1361-1372.

Trouton A, Spinath FM, Plomin R (2002). Twins Early Development Study (TEDS): a multivariate, longitudinal genetic investigation of language, cognition and behavior problems in childhood. Twin Research and Human Genetics 5, 444-448.

Trzaskowski M, Zavos HM, Haworth CM, Plomin R, Eley TC (2012). Stable genetic influence on anxiety-related behaviours across middle childhood. Journal of Abnormal Child Psychology 40, 85-94.
Uher R, Heyman I, Mortimore C, Frampton I, Goodman R (2007). Screening young people for obsessive-compulsive disorder. British Journal of Psychiatry 191, 353-354.

van Grootheest DS, Bartels M, Cath DC, Beekman AT, Hudziak JJ, Boomsma DI (2007). Genetic and environmental contributions underlying stability in childhood obsessive-compulsive behavior. Biological Psychiatry 61, 308-315.

van Grootheest DS, Bartels M, Van Beijsterveldt CE, Cath DC, Beekman AT, Hudziak JJ, Boomsma DI (2008). Genetic and environmental contributions to self-report obsessive-compulsive symptoms in Dutch adolescents at ages 12, 14, and 16. Journal of the American Academy of Child and Adolescent Psychiatry 47, 1182-1188.

van Grootheest DS, Cath D, Hottenga JJ, Beekman AT, Boomsma DI (2009). Genetic factors underlie stability of obsessive-compulsive symptoms. Twin Research and Human Genetics 12, 411-419.

van Grootheest DS, Cath DC, Beekman AT, Boomsma DI (2005). Twin studies on obsessive-compulsive disorder: a review. Twin Research and Human Genetics 8, 450-458.

Wagenmakers EJ, Farrell S (2004). AIC model selection using Akaike weights. Psychonomic Bulletin and Review 11, 192-196.

Zavos H, Gregory AM, Eley TC (2012). Longitudinal genetic analysis of anxiety sensitivity. Developmental Psychology 48, 204. 